Article

\title{
Succinyl-k-carrageenan Silver Nanotriangles Composite for Ammonium Localized Surface Plasmon Resonance Sensor
}

\author{
Mohd Hafiz Abu Bakar ${ }^{1}$, Nur Hidayah Azeman ${ }^{1, * \mathbb{D}}$, Nadhratun Naiim Mobarak ${ }^{2}$, Nur Afifah Ahmad Nazri ${ }^{1}$, \\ Tengku Hasnan Tengku Abdul Aziz ${ }^{3}$, Ahmad Rifqi Md Zain ${ }^{3}$ (D), Norhana Arsad ${ }^{1}$ (D) \\ and Ahmad Ashrif A. Bakar 1,4,*(D)
}

Citation: Abu Bakar, M.H.; Azeman, N.H.; Mobarak, N.N.; Ahmad Nazri, N.A.; Tengku Abdul Aziz, T.H.; Md Zain, A.R.; Arsad, N.; Bakar, A.A.A Succinyl-K-carrageenan Silver Nanotriangles Composite for Ammonium Localized Surface Plasmon Resonance Sensor. Polymers 2022, 14, 329. https://doi.org/ $10.3390 /$ polym 14020329

Academic Editors: Ieva Plikusiene and Almira Ramanavičienè

Received: 15 November 2021

Accepted: 12 January 2022

Published: 14 January 2022

Publisher's Note: MDPI stays neutral with regard to jurisdictional claims in published maps and institutional affiliations.

Copyright: (C) 2022 by the authors. Licensee MDPI, Basel, Switzerland. This article is an open access article distributed under the terms and conditions of the Creative Commons Attribution (CC BY) license (https:// creativecommons.org/licenses/by/ $4.0 /)$
1 Photonics Technology Laboratory, Department of Electrical, Electronic and Systems Engineering, Faculty of Engineering and Built Environment, Universiti Kebangsaan Malaysia, Bangi 43600, Selangor, Malaysia; hafiz.bujei95@gmail.com (M.H.A.B.); afifahnazri063@gmail.com (N.A.A.N.); noa@ukm.edu.my (N.A.)

2 Department of Chemical Sciences, Faculty of Science and Technology, Universiti Kebangsaan Malaysia, Bangi 43600, Selangor, Malaysia; nadhratunnaiim@ukm.edu.my

3 Institute of Microengineering and Nanoelectronics, Universiti Kebangsaan Malaysia, Bangi 43600, Selangor, Malaysia; hasnanaziz@ukm.edu.my (T.H.T.A.A.); rifqi@ukm.edu.my (A.R.M.Z.)

4 Institut Islam Hadhari, Universiti Kebangsaan Malaysia, Bangi 43600, Selangor, Malaysia

* Correspondence: nhidayah.az@ukm.edu.my (N.H.A.); ashrif@ukm.edu.my (A.A.A.B.)

\begin{abstract}
This research investigates the physicochemical properties of biopolymer succinyl-k-carrageenan as a potential sensing material for $\mathrm{NH}_{4}{ }^{+}$Localized Surface Plasmon Resonance (LSPR) sensor. Succinyl-k-carrageenan was synthesised by reacting $\mathrm{k}$-carrageenan with succinic anhydride. FESEM analysis shows succinyl- $\mathrm{k}$-carrageenan has an even and featureless topology compared to its pristine form. Succinyl-k-carrageenan was composited with silver nanoparticles (AgNP) as LSPR sensing material. AFM analysis shows that AgNP-Succinyl-k-carrageenan was rougher than AgNP-Succinyl$\mathrm{K}$-carrageenan, indicating an increase in density of electronegative atom from oxygen compared to pristine $\mathrm{k}$-carrageenan. The sensitivity of AgNP-Succinyl-k-carrageenan LSPR is higher than AgNP-k-carrageenan LSPR. The reported LOD and LOQ of AgNP-Succinyl-k-carrageenan LSPR are 0.5964 and 2.7192 ppm, respectively. Thus, AgNP-Succinyl-k-carrageenan LSPR has a higher performance than AgNP-K-carrageenan LSPR, broader detection range than the conventional method and high selectivity toward $\mathrm{NH}_{4}{ }^{+}$. Interaction mechanism studies show the adsorption of $\mathrm{NH}_{4}{ }^{+}$on $\mathrm{K}$-carrageenan and succinyl-k-carrageenan were through multilayer and chemisorption process that follows Freundlich and pseudo-second-order kinetic model.
\end{abstract}

Keywords: polysaccharide; carrageenan; surface plasmon resonance; ammonium ion; adsorbent; isotherm

\section{Introduction}

Ammonia $\left(\mathrm{NH}_{3}\right)$ is an essential source of nitrogen for marine phytoplankton [1]. It is readily dissolved in water to produce ammonium ions $\left(\mathrm{NH}_{4}{ }^{+}\right)$. An excessive amount of $\mathrm{NH}_{4}{ }^{+}$in water leads to significant ecological effects such as algae bloom in the water system, oxygen reduction in water, and eventual ruin of the ecological balance of the water system. High levels of $\mathrm{NH}_{4}{ }^{+}$in water systems come mainly from agricultural activities, industrial factories, mines, and sewage pollution [2].

The localized surface plasmon resonance (LSPR) sensing method is an evergreen technology and a susceptible optical method for chemical and biochemical analysis. LSPR uses collective free electron oscillation in metallic nanoparticles driven by an electromagnetic wave from incident light of a specific wavelength at the monometallic surface [3,4]. LSPR has been widely used for cationic detection such as $\mathrm{Pb}^{2+}, \mathrm{Cr}^{6+}$, and $\mathrm{Fe}^{2+}$. Incorporation of LSPR with a sensing material such as polymers for enhancement of LSPR performance is vital. Many researchers used polysaccharides due to their polycationic nature, which easily 
attaches metal nanoparticles to their surface via electrostatic interaction $[4,5]$. Because of their inexpensive, biodegradable, non-toxic, and environmentally friendly properties, carrageenan is the most appealing polymer among natural polymeric materials.

$\mathrm{k}$-carrageenan can be extracted from red seaweeds, where it is made up of a sulphate group per disaccharide unit with 4-linked 3,6-anhydro- $\alpha$-D-galactose and 3-linked$\beta$-D-galactose repeating units [6]. Recently, $\mathrm{k}$-carrageenan has been extensively used in research due to the high number of active sites such as hydroxyl and sulphate groups. $\mathrm{K}$-carrageenan has been studied for heavy metal adsorbent in LSPR sensors, mercury ion colorimetric detectors, and as a host in polymer electrolyte application [7]. Because of the existence of extra oxygen atoms provided by hydroxyl $(\mathrm{O}-\mathrm{H})$ and sulfate $(\mathrm{O}=\mathrm{S}=\mathrm{O})$ groups in the k-carrageenan structure, the sensor performance of LSPR is better when utilising $\mathrm{k}$-carrageenan as a sensing material in comparison to chitosan [3]. These groups enable the formation of a coordination bond with cation. To further improve the performance of $k$-carrageenan as a sensing material, chemical modification is necessary to achieve this objective. The effect of hydroxyl group substitution was studied with other oxygen-rich substituents to coordinate with cation [8]. The functional group's substitution in k-carrageenan structure can enhance its physiochemical properties. When compared to pristine carrageenan, modified carrageenan's ionic conductivity may increase by three orders of magnitude.

Bakar et al. successfully synthesized succinyl-k-carrageenan by reacting succinic anhydride with $\mathrm{k}$-carrageenan in a one-step reaction method [7]. It was reported that succinyl-k-carrageenan increased the performance of the polysaccharide. It facilitated the degree of ion dissociation and ion mobility since the electronegative atom's addition increases the interaction with cation in a salt solution. The addition of the succinyl group in $\mathrm{k}$-carrageenan provides two carbonyl moieties where it gives more electronegative sites for interaction than the carboxymethyl group. Thus, it can be further studied as a potential active material for $\mathrm{NH}_{4}{ }^{+}$interaction in the LSPR sensing technique.

Therefore, we report a novel, triangular AgNP LSPR sensor based on biopolymer succinyl-k-carrageenan for the detection of $\mathrm{NH}_{4}{ }^{+}$ions. Due to the increased electronegative active site in succinyl-k-carrageenan, it is expected the succinyl-k-carrageenan operates better than the pristine $\mathrm{k}$-carrageenan LSPR sensor. The succinyl- $\mathrm{k}$-carrageenan was established in a report by Bakar et al. [7]; thus, molecular characterization is not reported in this work. This research focuses on studying the physicochemical properties of succinyl$\kappa$-carrageenan and evaluating its performance as a potential active material for the $\mathrm{NH}_{4}{ }^{+}$ LSPR sensor. The succinyl-k-carrageenan's properties were investigated and compared with pristine k-carrageenan using Atomic Force Microscopy (AFM) and Field Emission Scanning Electron Microscope (FESEM). Then, the LSPR sensor performance utilizing the suggested sensing material to detect $\mathrm{NH}_{4}{ }^{+}$was evaluated. Finally, the isotherm and kinetic study were conducted to analyse and predict the succinyl-k-carrageenan surface interaction mechanism with $\mathrm{NH}_{4}{ }^{+}$.

\section{Materials and Methods}

\subsection{Material}

Industrial-grade k-carrageenan was taken from Tacara Sdn Bhd (Sabah, Malaysia) (TA150) (Mw: $12 \mathrm{kDa}$ ). Succinic anhydride, (3-Aminopropyl) triethoxysilane (APTES), acetone, acetonitrile, silver nitrate $\left(\mathrm{AgNO}_{3}\right)$, ammonium chloride, trisodium citrate, sodium borohydride $\left(\mathrm{NaHB}_{4}\right)$, hydrogen peroxide $\left(\mathrm{H}_{2} \mathrm{O}_{2}\right)$, calcium nitrate tetrahydrate, manganese sulfate monohydrate, zinc nitrate hexahydrate, and ammonium chloride $\left(\mathrm{NH}_{4} \mathrm{Cl}\right)$ were bought from Sigma-Aldrich. Lead standard solution and iron nitrate nonahydrate were bought from Merck. All solvents were used without purification.

\subsection{Preparation of Succinyl Kappa-Carrageenan}

Succinyl-k-carrageenan was synthesised according to the previous technique established in [7]. One gram of $\mathrm{k}$-carrageenan was dissolved in $200 \mathrm{~mL}$ of distilled water and 
transferred into the conical flask. Two grams of succinic anhydride was dissolved in $20 \mathrm{~mL}$ of acetone and dropped into the flask at room temperature for $30 \mathrm{~min}$. The reaction was continued at $40{ }^{\circ} \mathrm{C}$ for $24 \mathrm{~h}$. The mixture was cooled down to room temperature once the reaction was completed. Additional acetone was added to the mixture before acetonitrile to precipitate the compound. The unreacted succinic anhydride can be eliminated by filtering and washing the precipitate with acetonitrile. Finally, the precipitate was dried in a desiccator for $12 \mathrm{~h}$.

\subsection{Preparation of $A g N P$}

Preparation of AgNP followed the procedure established by $[9,10]$. An amount of $0.2 \mathrm{~mL}$ of the $0.05 \mathrm{M} \mathrm{AgNO}_{3}$ solution was added into deionized water $(96.56 \mathrm{~mL})$. The mixture was stirred at $900 \mathrm{rpm}$. Then, $2.0 \mathrm{~mL}$ of $75 \mathrm{mM}$ trisodium citrate and $0.24 \mathrm{~mL}$ of $30 \% \mathrm{H}_{2} \mathrm{O}_{2}$ were added into the mixture. Next, $1.0 \mathrm{~mL}$ of $\mathrm{NaBH}_{4}$ was immediately injected into the mix. The colour of the mixture was observed until the dark blue colour of the AgNP solution formed. Lastly, the dark blue solution was centrifuged at $4000 \mathrm{rpm}$ for $1 \mathrm{~h}$ to obtain the dark blue sediment and collected to acquire about $2 \mathrm{~mL}$ of the blue sediment.

\subsection{Preparation of AgNP LSPR Glass Slide via the Composite Method}

The substrate was prepared using $1 \mathrm{~cm} \times 1 \mathrm{~cm}$ quartz glass. The substrate was washed using liquid detergent and deionised water. Then, the substrate was immersed in piranha solution $\left(1: 3=\mathrm{H}_{2} \mathrm{O}_{2}: \mathrm{H}_{2} \mathrm{SO}_{4}\right)$ for an hour. Later, the substrate was immersed and sonicated in acetone and ethanol for $15 \mathrm{~min}$, respectively. Next, the substrate was immersed in 5\% APTES solution for another hour. Rinse the substrate with ethanol and dry it on a hotplate at $100{ }^{\circ} \mathrm{C}$ for $30 \mathrm{~min}$.

Meanwhile, AgNP-succinyl-k-carrageenan and AgNP- $\mathrm{k}$-carrageenan composites were prepared by mixing $2 \%$ of succinyl-k-carrageenan and $k$-carrageenan into $6 \mathrm{~mL}$ of diluted AgNP sediment. Then about $0.7 \%$ of glacial acetic acid was added to the mixture to help in dissolving the polymer. The mixture was stirred overnight and sonicated at $40^{\circ} \mathrm{C}$ for $15 \mathrm{~min}$ to dissolve the compounds. Then, $0.1 \mathrm{~mL}$ of the composite was coated on a $1 \mathrm{~cm} \times 1 \mathrm{~cm}$ glass slide using a spin coater with $1500 \mathrm{rpm}$ and dried on a hot plate. The process was repeated twice. The coated substrates were analysed using LSPR. Figure 1 depicts the procedure preparation of the glass slide using the composite mixture.

\subsection{Experimental Setup for Detection of $\mathrm{NH}_{4}{ }^{+}$Ion Using LSPR Sensor}

In this research, the method of measurement using reflectance LSPR was more suitable due to the nature of carrageenan and its derivative since pristine $k$-carrageenan and succinyl- $\mathrm{K}-$ carrageenan is non-transparent [3]. $\mathrm{NH}_{4}{ }^{+}$could be easily detected by dropping the $\mathrm{NH}_{4}{ }^{+}$solution on the surface of AgNP-K-carrageenan and AgNP-succinyl-kcarrageenan substrate for LSPR analysis.

The system consisted of a light source from Ocean Optic (DH-2000-BAL, Ocean Optics Inc., Dunedin, FL, USA) and a light sensor (HR4000CG-UV-NIR) from Ocean Optics (Dunedin, FL, USA to measure the optical response. The fibre core of the reflection probe used in this experiment was $600 \mu \mathrm{m}$ with a numerical aperture of 0.22 . A reflection probe was connected to the light source and spectrometer. The probe was adjusted to an optimum distance above the sample, as shown in Figure 2. 


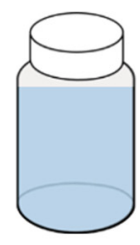

$2 \%$ of $\kappa$-carrageenan /derivative was added into

$6 \mathrm{ml}$ of diluted $\mathrm{AgNP}$ solution and $0.7 \%$ acetic acid was added into the mixture.

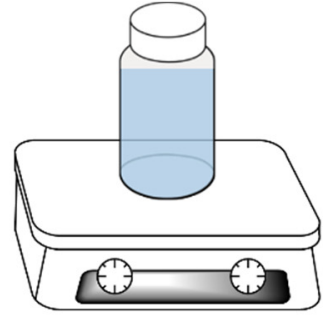

The composite mixture was stirred overnight and sonicated at $40{ }^{\circ} \mathrm{C}$ for 15 minutes.

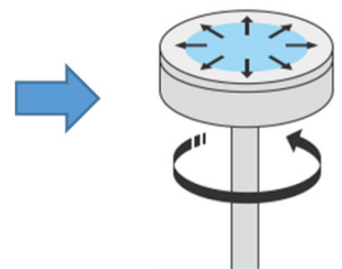

Drop $0.1 \mathrm{ml}$ composite onto the functionalized $1 \mathrm{~cm} \times 1 \mathrm{~cm}$ glass substrate at certain speed of rotation.

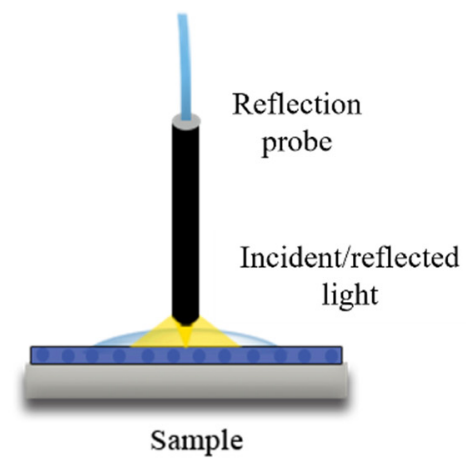

The coated substrate was analyzed using LSPR at different concentration of ammonium ion solution.

Figure 1. Experimental procedure for preparation of substrate coated with AgNP-K-carrageenan and AgNP-succinyl-k-carrageenan composites.

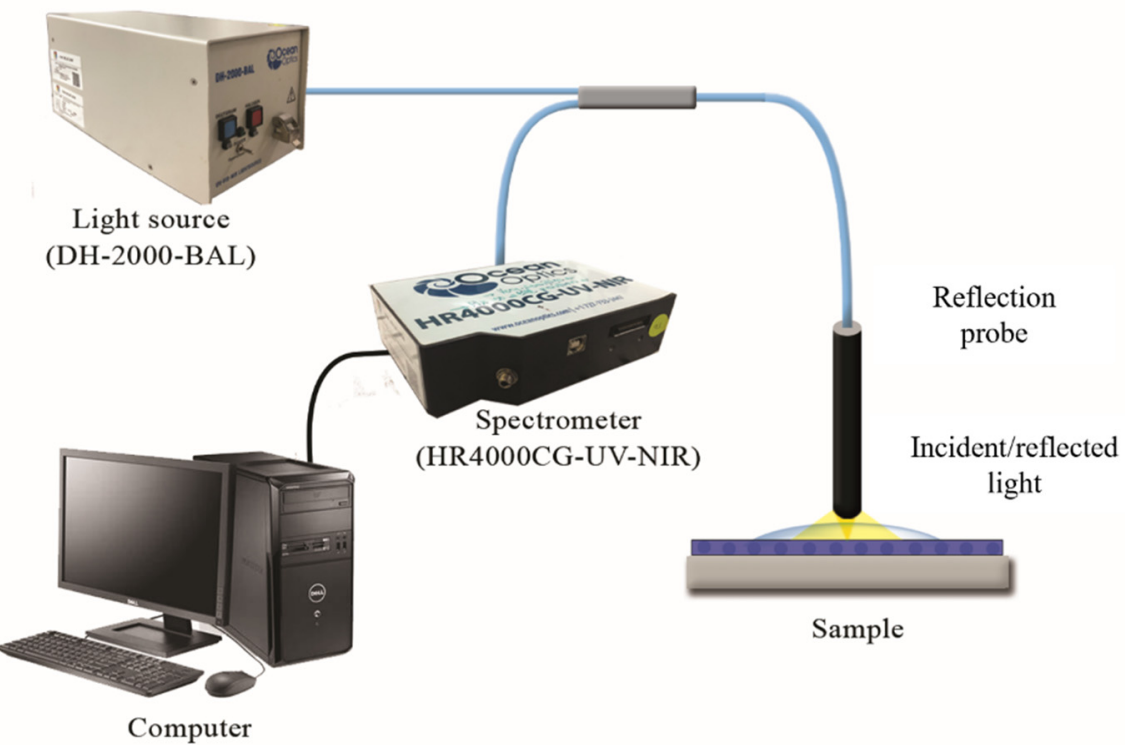

Figure 2. Experimental setup for detection of $\mathrm{NH}_{4}{ }^{+}$using LSPR sensor.

\subsection{Characterisation}

The morphology properties of succinyl-k-carrageenan and $k$-carrageenan were analysed using FESEM coupled D8 Quest SC-XRD (Bruker, MA, USA) at $15 \mathrm{Kv}$ with a magnification of $5000 \times, 20,000 \times$, and 50,000 $\times$. The surface roughness of succinyl-k-carrageenan and K-carrageenan was investigated using AFM NX-10 (Park Systems Corp., Suwon, Korea). 
The XE Image Processing software (Park Systems Corp., 4th Edition) was used to obtain average surface roughness. Measurements are based on the heights of peaks and valleys on the surface.

\subsection{Interaction Mechanism Study}

The procedure of $\mathrm{NH}_{4}{ }^{+}$detection was conducted using the standard method Nesslerisation by UV-Visible absorbance. $\mathrm{NH}_{4} \mathrm{Cl}$ was utilised as an analyte. A 1000 ppm stock solution of $\mathrm{NH}_{4}{ }^{+}$as made by diluting $1.486 \mathrm{~g}$ of dried $\mathrm{NH}_{4} \mathrm{Cl}$ salt in $500 \mathrm{~mL}$ of deionised water. Then, a series of dilutions ranging from $0.05 \mathrm{ppm}$ to $10 \mathrm{ppm}$ were prepared.

The effective dosage on the adsorption capacity of $\mathrm{NH}_{4}{ }^{+}$were investigated in $20 \mathrm{~mL}$ of 1 ppm $\mathrm{NH}_{4}{ }^{+}$solution for $60 \mathrm{~min}$ as standardised equilibrium time for both compounds by varying the mass of compounds at $360 \mathrm{rpm}$. Meanwhile, the initial $\mathrm{NH}_{4}{ }^{+}$concentration effect was conducted by varying the concentration $20 \mathrm{~mL}$ of $\mathrm{NH}_{4}{ }^{+} \cdot \mathrm{NH}_{4}{ }^{+}$was investigated within the range of $0.05-2.0 \mathrm{ppm}$ at $360 \mathrm{rpm}$ for $60 \mathrm{~min}$ using $0.1 \mathrm{~g}$ as an optimum adsorption mass for $\kappa$-carrageenan and succinyl- $\kappa$-carrageenan. Meanwhile, the effect of interaction time between pristine $\kappa$-carrageenan and succinyl- $\kappa-$ carrageenan on the adsorption capacity of $\mathrm{NH}_{4}{ }^{+}$was investigated by varying the interaction time from 10-120 min.

The mixture was filtered using a $0.22 \mu \mathrm{m}$ membrane syringe filter, rinsed, and the filtrate was transferred into a round-bottomed flask. Next, $1 \mathrm{~mL}$ of dechlorinating agent and $2 \mathrm{~mL}$ of borate buffer was added to the mixture. The mixed solution was then $75 \%$ distilled into $5 \mathrm{~mL}$ of $0.3 \mathrm{M}$ sulfuric acid using Kjeldahl apparatus to remove any trace of another compound. A few drops of $0.05 \mathrm{M} \mathrm{NaOH}$ was added to the sample to neutralise the sample. An amount of $1.2 \mathrm{~mL}$ of Nessler Reagent was dropped into the collected sample to develop the yellow-orange solution. UV-Vis spectrometer (OceanOptic ${ }^{\circledR}$ ) was used to measure the absorbance of the complex solution at $425 \mathrm{~nm}$ using $1 \mathrm{~m} \times 1 \mathrm{~m}$ cuvette. The data from the absorbance experiment were collected and analysed to study the isotherm properties based on Langmuir and Freundlich model. The amount of adsorbed $\mathrm{NH}_{4}{ }^{+}$onto carrageenan compound at equilibrium time, $q_{e}(\mathrm{mg} / \mathrm{g})$, was calculated using the following equation:

$$
q_{e}=\frac{C_{0}-C_{e}}{m} \times V
$$

where $C_{0}(\mathrm{mg} / \mathrm{L})$ is the initial concentration of $\mathrm{NH}_{4}{ }^{+}, \mathrm{C}_{e}(\mathrm{mg} / \mathrm{L})$ is the $\mathrm{NH}_{4}{ }^{+}$concentration at equilibrium time, $V(\mathrm{~L})$ is the volume of $\mathrm{NH}_{4}{ }^{+}$used, and $m(\mathrm{~g})$ is the mass of pristine $\kappa$-carrageenan and succinyl-k-carrageenan.

The Langmuir isotherm assumes monolayer adsorption onto an adsorbent surface. The linear form of Langmuir adsorption isotherm can be expressed as [11,12]:

$$
\frac{c_{e}}{q_{e}}=\frac{1}{q_{\max } K_{L}}+\frac{c_{e}}{q_{\max }}
$$

where;

$K_{L}=$ adsorption equilibrium constant $(\mathrm{L} / \mathrm{mg})$

$q_{\max }=$ maximum ammonium ion adsorption capacity $(\mathrm{mg} / \mathrm{g})$

$q_{e}=$ adsorption capacity $(\mathrm{mg} / \mathrm{g})$ at equilibrium

The value of $q_{\max }$ is obtained from a linear plot of $C_{e} / q_{e}$ versus $C_{e}$.

Meanwhile, the Freundlich isotherm model described adsorption on heterogeneous systems and assumed that the adsorption occurs on-site with different adsorption energies. The adsorption occurs in multilayer, and the Freundlich isotherm equation was given as follows [11,12]:

$$
q_{e}=K_{F} C_{e}^{\frac{1}{n}}
$$


This equation could be written in linear form as follows:

$$
\log q_{e}=\log K_{F}+\frac{1}{n} \log C_{e}
$$

$K_{F}=$ adsorption capacity

$n=$ adsorption intensity, respectively.

$K_{F}$ and $n$ are obtained from the slope and intercept of the linear $\log q_{e}$ versus $\log C_{e}$.

The effect of stirring time was investigated by using $0.1 \mathrm{~g}$ of $\mathrm{k}$-carrageenan and succinyl-k-carrageenan as optimum adsorption mass of $\mathrm{NH}_{4}{ }^{+}$. The adsorption was investigated using $20 \mathrm{~mL}$ of $2.0 \mathrm{ppm}$ as the optimum concentration of $\mathrm{NH}_{4}{ }^{+}$at $25^{\circ} \mathrm{C}$ at $360 \mathrm{rpm}$ for desired stirring time. The amount of adsorbed $\mathrm{NH}_{4}{ }^{+}$onto carrageenan compound at a time, $q_{t}(\mathrm{mg} / \mathrm{g})$, was calculated using the following equation:

$$
q_{t}=\frac{C_{0}-C_{t}}{m} \times V
$$

where $C_{0}(\mathrm{mg} / \mathrm{L})$ is the initial concentration of $\mathrm{NH}_{4}{ }^{+}, \mathrm{C}_{t}(\mathrm{mg} / \mathrm{L})$ is the $\mathrm{NH}_{4}{ }^{+}$concentration at the time, $t(\mathrm{~min}), V(\mathrm{~L})$ is the volume of $\mathrm{NH}_{4}{ }^{+}$used, and $m(\mathrm{~g})$ is the mass of pristine $\mathrm{k}$-carrageenan and succinyl-k-carrageenan.

To examine the kinetic mechanism, the pseudo-first-order and the pseudo-secondorder kinetic models were used for analyses and comparison. The pseudo-first-order rate equation are as follows [13,14]:

$$
\log \left(q_{e}-q_{t}\right)=\log q_{e}-\frac{k_{1} t}{2.303}
$$

The pseudo-second-order rate equation was given as below [13,14]:

$$
\frac{t}{q_{t}}=\frac{1}{k_{2} q_{e}^{2}}+\frac{t}{q_{e}}
$$

where;

$q_{t}=$ the adsorption capacity at time $\mathrm{t}(\mathrm{min})$.

$k_{1}=$ adsorption rate constants of pseudo-first-order $\left(\mathrm{min}^{-1}\right)$

$k_{2}=$ pseudo-second-order adsorption rates $\left(\mathrm{g} \mathrm{mg}^{-1} \mathrm{~min}^{-1}\right)$

\section{Results and Discussion}

This section may be divided by subheadings. It should provide a concise and precise description of the experimental results, their interpretation, as well as the experimental conclusions that can be drawn.

\subsection{Surface Studies of Sensing Materials for LSPR}

In LSPR, AgNP was used to generate intense LSPR responses. In this study, AgNP was combined with $\mathrm{k}$-carrageenan and succinyl- $\mathrm{k}$-carrageenan, respectively, to increase the performance of LSPR. To further understand how the sensing material interacts with $\mathrm{NH}_{4}{ }^{+}$, FESEM was used to carry out the morphological study. The surface morphologies of bare $\mathrm{AgNP}, \mathrm{k}$-carrageenan and succinyl-k-carrageenan substrate are shown in Figure 3. Figure 3a shows the FESEM image of triangular nanoparticle were successfully coated on the surface of glass substrate proving the fruitful synthesis of AgNP in the form of triangular shape using procedure reported in $[9,10]$. Meanwhile, Figure $3 b$ shows the surface morphology of the $\mathrm{k}$-carrageenan film with uneven and featureless topology compared to succinyl-kcarrageenan. The surface morphology of succinyl-k-carrageenan (Figure 3c) was even and smooth. 

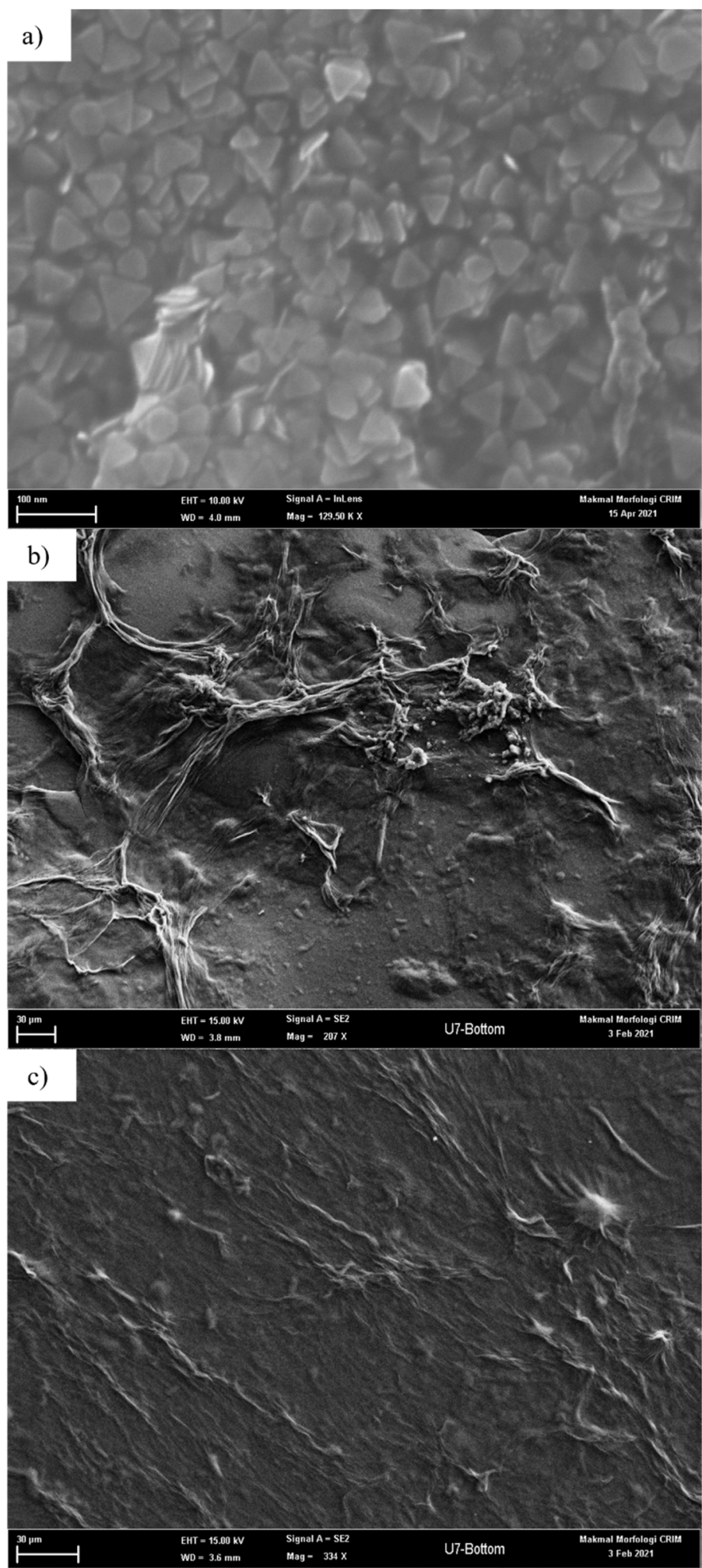

Figure 3. FESEM surface morphologies of the (a) AgNP (b) k-carrageenan and (c) succinyl-kcarrageenan films.

Figure 4 illustrate the three-dimensional (3D) image of (a) AgNP, (b) AgNP-k-carrageenan, and (c) AgNP-succinyl-k-carrageenan on the surface of a salinized glass substrate using AFM. The variation topology can be differentiated by calculating the average roughness $\left(r_{a}\right)$ of each figure using XE Image Processing software. The average roughness of bare 
AgNP, AgNP-к-carrageenan and AgNP-succinyl-k-carrageenan (Table 1). Based on $\mathrm{r}_{\mathrm{a}}$ value, the surface roughness increased after AgNP was incorporated with $k$-carrageenan and succinyl-k-carrageenan. Furthermore, it was observed that the average surface roughness of AgNP-succinyl-k-carrageenan in Figure $4 \mathrm{c}$ was up to seven times rougher as compared to AgNP- $\mathrm{k}$-carrageenan in Figure $4 \mathrm{~b}$. This could be attributed to the extra oxygen atom in succinyl- $\mathrm{k}$-carrageenan compared to the structure of $k$-carrageenan as confirmed by the FTIR in research conducted by [7]. This large difference in $r_{a}$ was also contributed to by the high degree of substitution during synthesis of succinyl-k-carrageenan whereby more than one hydroxyl group in pristine $\mathrm{k}$-carrageenan was substituted with the higher oxygen atom succinyl group [7]. This research pattern was reported previously, whereby adding oxygen-containing compounds increases the surface roughness up to 15 times compared to precursor compound [4,15-17]. The result from the average surface roughness from the use of succinyl-k-carrageenan as sensing material is essential for further study of sensitivity improvement, whereby extra site of $\mathrm{C}=\mathrm{O}$ from carbonyl group in succinyl moieties provide more interaction with $\mathrm{NH}_{4}{ }^{+}$, hence leading to higher sensor sensitivity $[3,17]$.
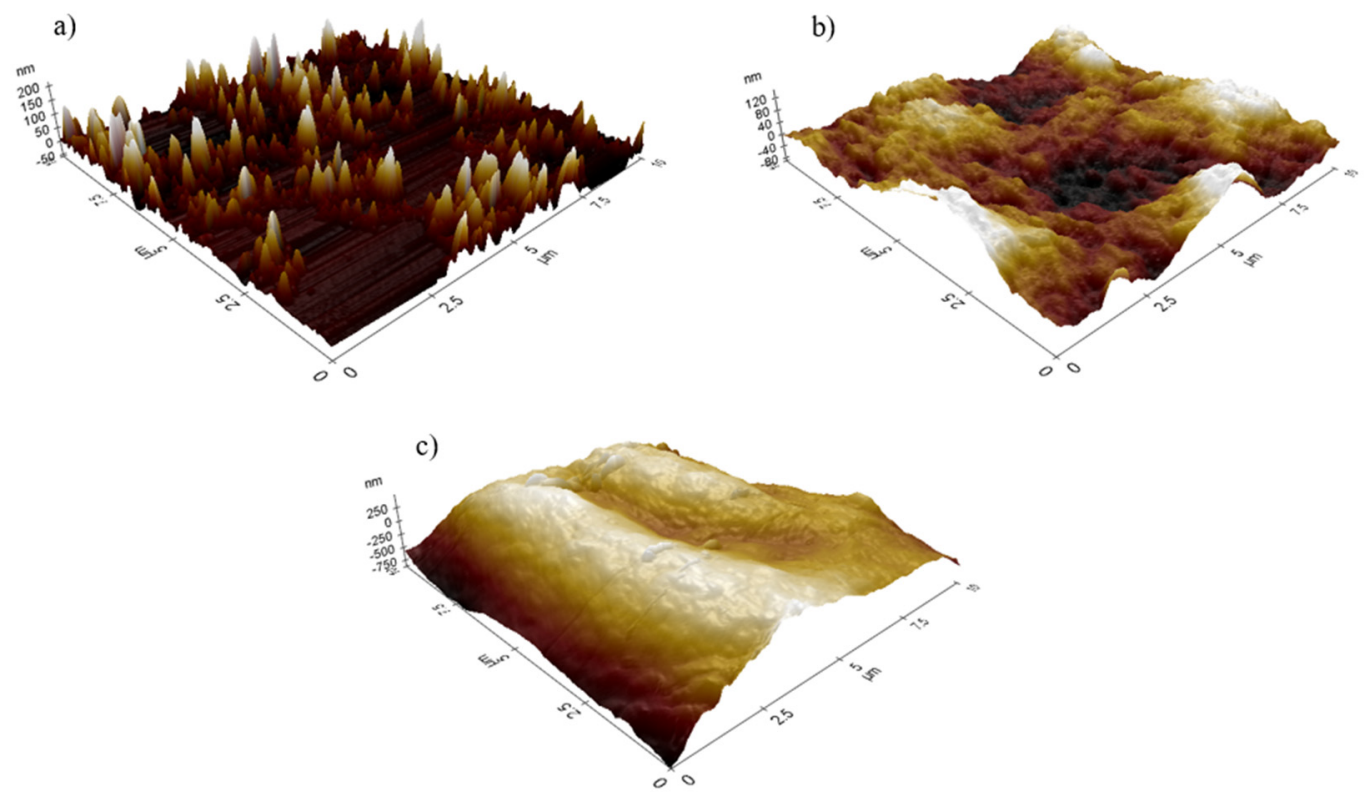

Figure 4. Surface roughness of the (a) bare AgNP, (b) AgNP-K-carrageenan, and (c) AgNP-succinyl-kcarrageenan films.

Table 1. Average surface roughness of bare AgNP, AgNP-k-carrageenan, and AgNP-succinyl-kcarrageenan.

\begin{tabular}{cc}
\hline Compound & Average Surface Roughness, $\mathbf{r}_{\mathbf{a}}(\mathbf{n m})$ \\
\hline AgNP & 20.777 \\
AgNP- $\kappa-$ carrageenan & 27.265 \\
AgNP-succinyl- $\kappa$-carrageenan & 198.535 \\
\hline
\end{tabular}

\subsection{Detection of $\mathrm{NH}_{4}{ }^{+}$Using LSPR Technique}

AgNP-k-carrageenan and AgNP-succinyl-k-carrageenan composites were used as sensing materials to develop the LSPR sensor to detect $\mathrm{NH}_{4}{ }^{+}$. The performance of these two materials was compared with bare AgNP based on peak wavelength shift. The present study used deionized water (DI) as the baseline for bare AgNP, AgNP-k-carrageenan, and AgNP-succinyl-k-carrageenan composites. Figure 5a reveals the spectrum of bare AgNP, which shows the narrow peak at different concentrations of $\mathrm{NH}_{4}{ }^{+}$. However, the bare AgNP does not show any distinct peak shifting ranging from 0.1-10.0 ppm. Meanwhile, Figure $5 \mathrm{~b}$ 
represents the spectrum of AgNP-k-carrageenan composite with distinct peak shifting when exposed to the different $\mathrm{NH}_{4}{ }^{+}$concentrations. The reflectance peak is red-shifted to $449.42,449.68,449.95,449.42,450.47,450.73$, and 450.99 from the baseline $(448.11 \mathrm{~nm})$ for $0.1,0.4,0.8,1.0,4.0,6.0$, and $10.0 \mathrm{ppm}$, respectively. Figure $5 \mathrm{c}$ represents the LSPR spectrum of AgNP-succinyl-k-carrageenan composite when tested with different concentrations of $\mathrm{NH}_{4}{ }^{+}$. The peak spectra of the reflectance are red-shifted to $446.8,447.32,447.85,447.59$, $447.85,449.42,450.99$, and $453.35 \mathrm{~nm}$ from the baseline $(446.8 \mathrm{~nm})$ corresponding to $0.1,0.4$, $0.8,1.0,4.0,6.0$, and $10.0 \mathrm{ppm}$, respectively. A relationship study was conducted to validate the LSPR sensor's performance for bare AgNP, AgNP-k-carrageenan and AgNP-succinyl$\kappa$-carrageenan and the sensitivity of materials were studied as depicted in Figure 6.
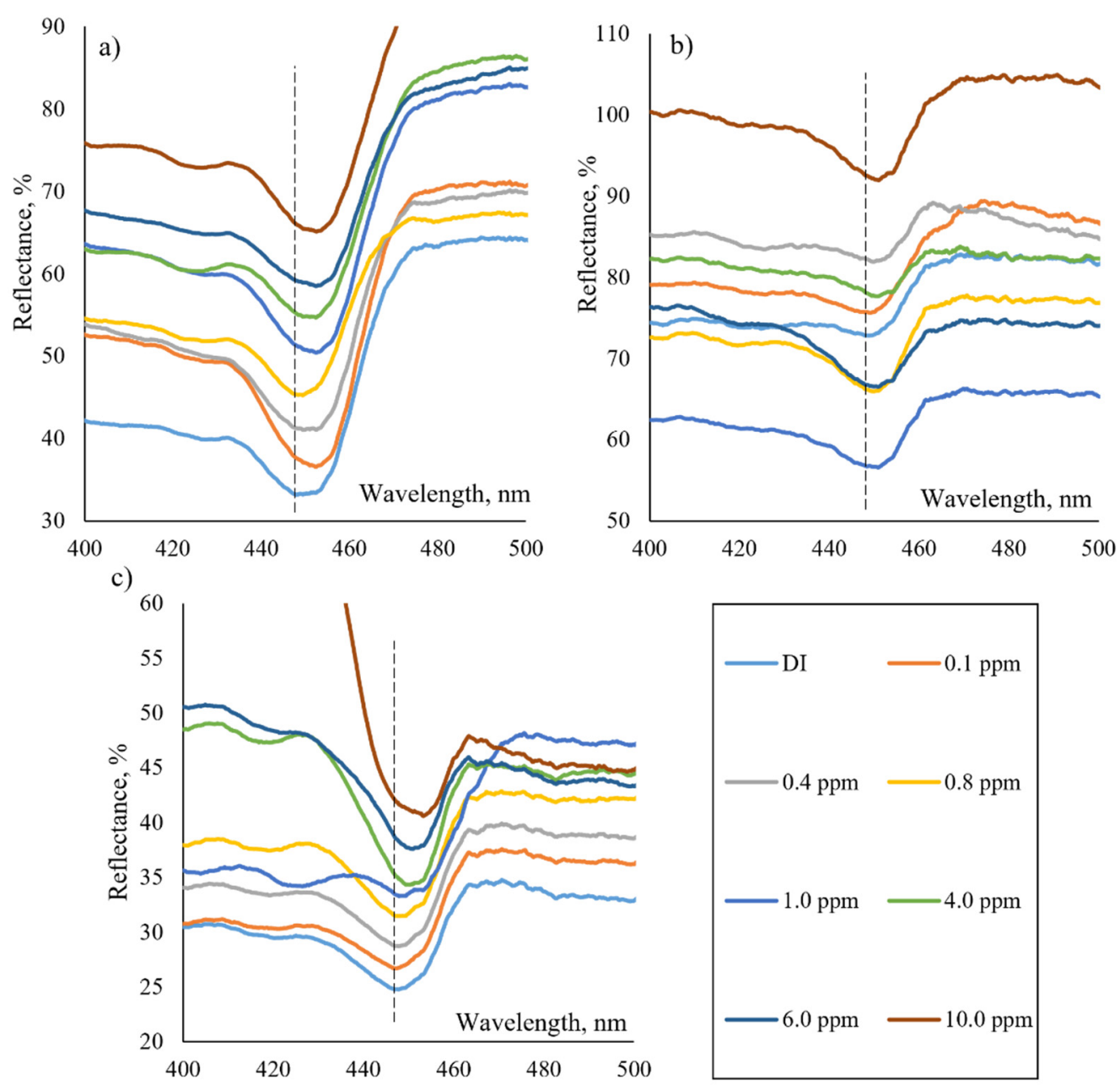

Figure 5. LSPR spectra for detection of $\mathrm{NH}_{4}{ }^{+}$at different concentration using (a) AgNP, (b) AgNP-Kcarrageenan, and (c) AgNP-succinyl-k-carrageenan composites.

The linear relationship study was carried out between bare AgNP, AgNP-k-carrageenan, and AgNP-succinyl-k-carrageenan composites with $\mathrm{NH}_{4}{ }^{+}$ion concentration, ranging from 0.1-10.0 ppm. Figure 6 demonstrates the wavelength shift $(\Delta \lambda)$ for bare AgNP, AgNP$\mathrm{k}$-carrageenan, and AgNP-succinyl-k-carrageenan composites for thrice measurements with different concentrations of $\mathrm{NH}_{4}{ }^{+}$ion. As a baseline, DI water was used to analyse the correlation coefficient $\left(R^{2}\right)$, and the sensor's sensitivity was determined from the slope of the graph $[3,18]$. Figure 6a observed that AgNP-succinyl-k-carrageenan composite shows excellent linearity with $R^{2}=0.9947$ when using sensing material to detect various concentrations of $\mathrm{NH}_{4}{ }^{+}$ion. In addition, the sensitivity of the AgNP-succinyl-kcarrageenan LSPR sensor was calculated to be $0.626 \mathrm{~nm} \mathrm{ppm}^{-1}$. Temporarily, Figure $6 \mathrm{~b}, \mathrm{c}$ 
show the graph of bare AgNP and AgNP- $\mathrm{k}$-carrageenan composite with the linearity of $\mathrm{R}^{2}=0.0999$ and $\mathrm{R}^{2}=0.8662$, and the calculated sensitivity of 0.0692 and $0.1061 \mathrm{~nm}$ $\mathrm{ppm}^{-1}$, respectively. Enhanced sensitivity was detected for AgNP-succinyl-k-carrageenan composite compared to AgNP-K-carrageenan composite and bare AgNP due to the higher density of electronegative atom in the succinyl-k-carrageenan functional group compared to $k$-carrageenan, as confirmed by AFM in Figure 4 and FTIR reported in [7]. These extra electronegative oxygen atoms provided more binding sites for $\mathrm{NH}_{4}{ }^{+}$ions; hence, higher sensitivity was achieved for AgNP-succinyl-k-carrageenan compared to AgNP- $\mathrm{k}-$ carrageenan. This phenomenon pattern was also described previously, where the substitution of the $\mathrm{k}$ carrageenan functional group with a more electronegative group increases the performance of the polysaccharides [6-8].

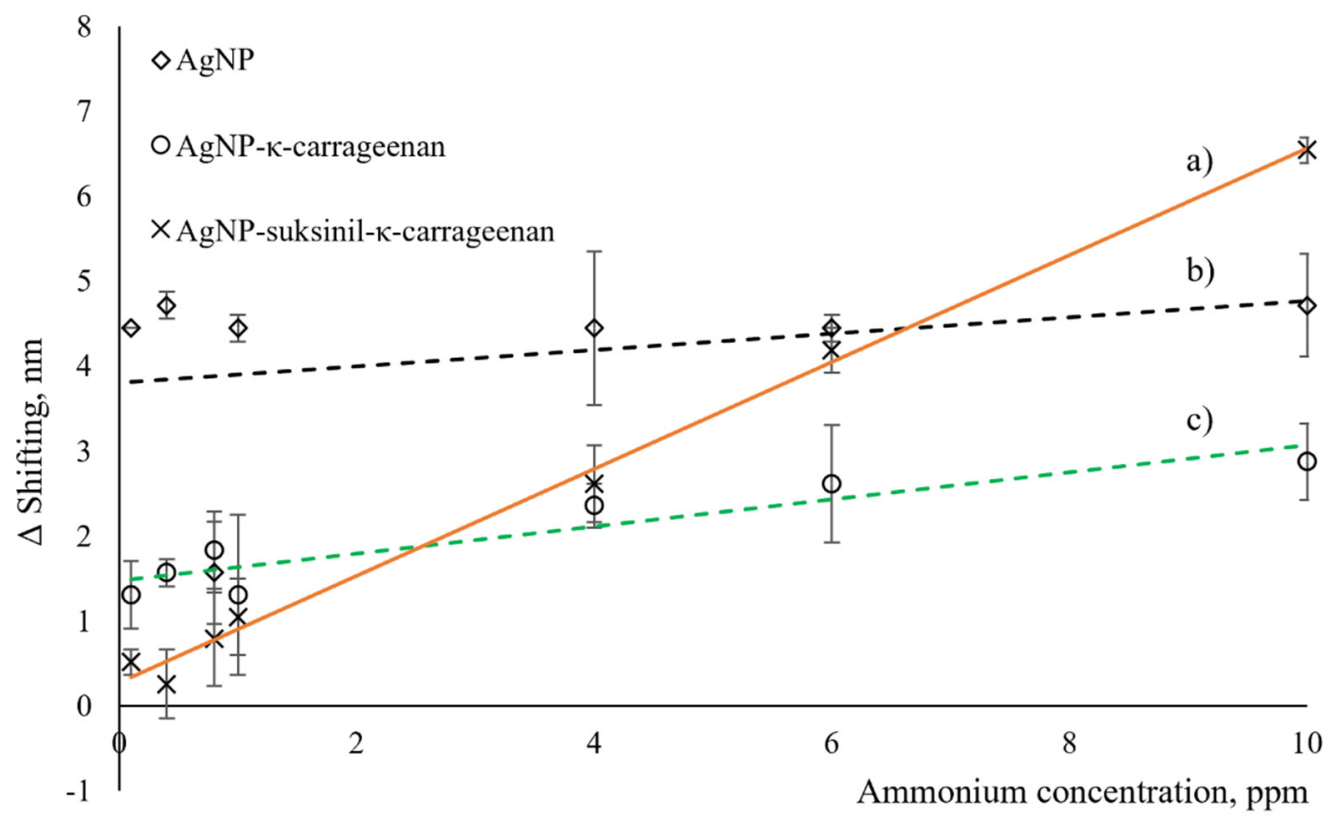

Figure 6. A linear relationship of (a) AgNP-succinyl-k-carrageenan composite (b) bare AgNP and (c) AgNP-K-carrageenan composite for $\mathrm{NH}_{4}{ }^{+}$sensing in the range of 0.1-10 ppm concentration.

Furthermore, it was observed that AgNP-succinyl-k-carrageenan shows lower limit of detection (LOD) and limits of quantification (LOQ) compared with AgNP-K-carrageenan, as shown in Table 2. This is due to the stronger interaction between AgNP-succinyl-Kcarrageenan with $\mathrm{NH}_{4}{ }^{+}$compared to AgNP-K-carrageenan [7]. Based on the LSPR sensor performance results, it is proven that AgNP-succinyl-k-carrageenan composite shows better performance toward $\mathrm{NH}_{4}{ }^{+}$ion detection than bare $\mathrm{AgNP}$ and $\mathrm{AgNP}-\mathrm{K}-$ carrageenan composite.

When compared to the standard approach for $\mathrm{NH}_{4}{ }^{+}$detection using Nessler and indophenol reagent, AgNP-succinyl-k-carrageenan LSPR has a broader detection range, detecting up to $10 \mathrm{ppm}$. Meanwhile, the Nessler and indophenol reagent standard methods can only detect $\mathrm{NH}_{4}{ }^{+}$up to 5 and 0.160 ppm, respectively [19]. In addition, the Nessler and indophenol reagent approaches are complex. They contain the hazardous mercury salt reagent and phenol, which is toxic. The present work can detect $\mathrm{NH}_{4}{ }^{+}$at a lower concentration range compared to other techniques such as electrochemical and colorimetric techniques. The proposed LSPR technique also comply with the detection range of $\mathrm{NH}_{4}{ }^{+}$ stated by the World Health Organization (WHO) $[20,21]$. 
Table 2. The performance and correlation coefficient $\mathrm{R}^{2}$ of AgNP, composite AgNP-k-carrageenan and composite AgNP-succinyl-k-carrageenan for NH4+ detection.

\begin{tabular}{|c|c|c|c|c|c|c|}
\hline Compound & $\begin{array}{l}\text { Sensitivity } \\
\left(\mathrm{nm}^{\mathrm{ppm}}{ }^{-1}\right)\end{array}$ & $\begin{array}{l}\text { Regression } \\
\qquad\left(R^{2}\right)\end{array}$ & $\begin{array}{l}\text { LOD } \\
(\mathrm{ppm})\end{array}$ & $\begin{array}{c}\text { LOQ } \\
\text { (ppm) }\end{array}$ & $\begin{array}{c}\text { Range of } \\
\text { Detection (ppm) }\end{array}$ & Reference \\
\hline AgNP & 0.0962 & 0.0999 & 20.7618 & 62.9146 & - & This work \\
\hline AgNP- $\mathrm{K}$-carrageenan & 0.1601 & 0.8662 & 2.7192 & 8.2400 & $2.7-6.0$ & This work \\
\hline $\begin{array}{l}\text { AgNP-succinyl-k- } \\
\text { carrageenan }\end{array}$ & 0.6289 & 0.9947 & 0.5964 & 2.7192 & $0.6-10.0$ & This work \\
\hline $\begin{array}{l}\text { Standard Method } \\
\text { Indophenol Reagent }\end{array}$ & - & - & 0.160 & - & $0.35-1.8$ & [19] \\
\hline $\begin{array}{l}\text { Standard Method } \\
\text { Nessler Reagent }\end{array}$ & - & - & 0.6 & - & $0.85-5.0$ & [19] \\
\hline $\begin{array}{l}\text { PANi, CPANI, Ag } \\
\text { (electrochemical) }\end{array}$ & - & - & - & - & $3.6-3550$ & [20] \\
\hline $\begin{array}{l}\mu \mathrm{PAD} \text { (colorimetric } \mathrm{pH} \\
\text { indicator) }\end{array}$ & - & 0.999 & 0.47 & - & $2.0-10.0$ & {$[21]$} \\
\hline
\end{tabular}

The selectivity test was performed to determine the sensing materials' affinity for the target analyte. To investigate the possibility of interference from other cations, the glass substrate coated with AgNP-succinyl-k-carrageenan was exposed to solutions containing other contaminant cations such as calcium $\left(\mathrm{Ca}^{2+}\right)$, iron $\left(\mathrm{Fe}^{3+}\right)$, potassium $\left(\mathrm{K}^{+}\right)$, manganese $\left(\mathrm{Mn}^{2+}\right)$, and lead $\left(\mathrm{Pb}^{2+}\right)$ at $6 \mathrm{ppm}$. Figure 7 indicates that the sensor probe has high selectivity for $\mathrm{NH}_{4}{ }^{+}$ions compared to other cations, as shown by the major difference in wavelength shift for $\mathrm{NH}_{4}{ }^{+}$. This might be due to the formation of extra hydrogen bonds between hydrogen in $\mathrm{NH}_{4}{ }^{+}$and oxygen atom in the succinyl-k-carrageenan structure. This hydrogen bond does not occur in other cation interference. This phenomenon is also supported by a few research whereby the hydrogen atom in $\mathrm{NH}_{4}{ }^{+}$can interact with electronegative oxygen atom via hydrogen bond [7,22,23].

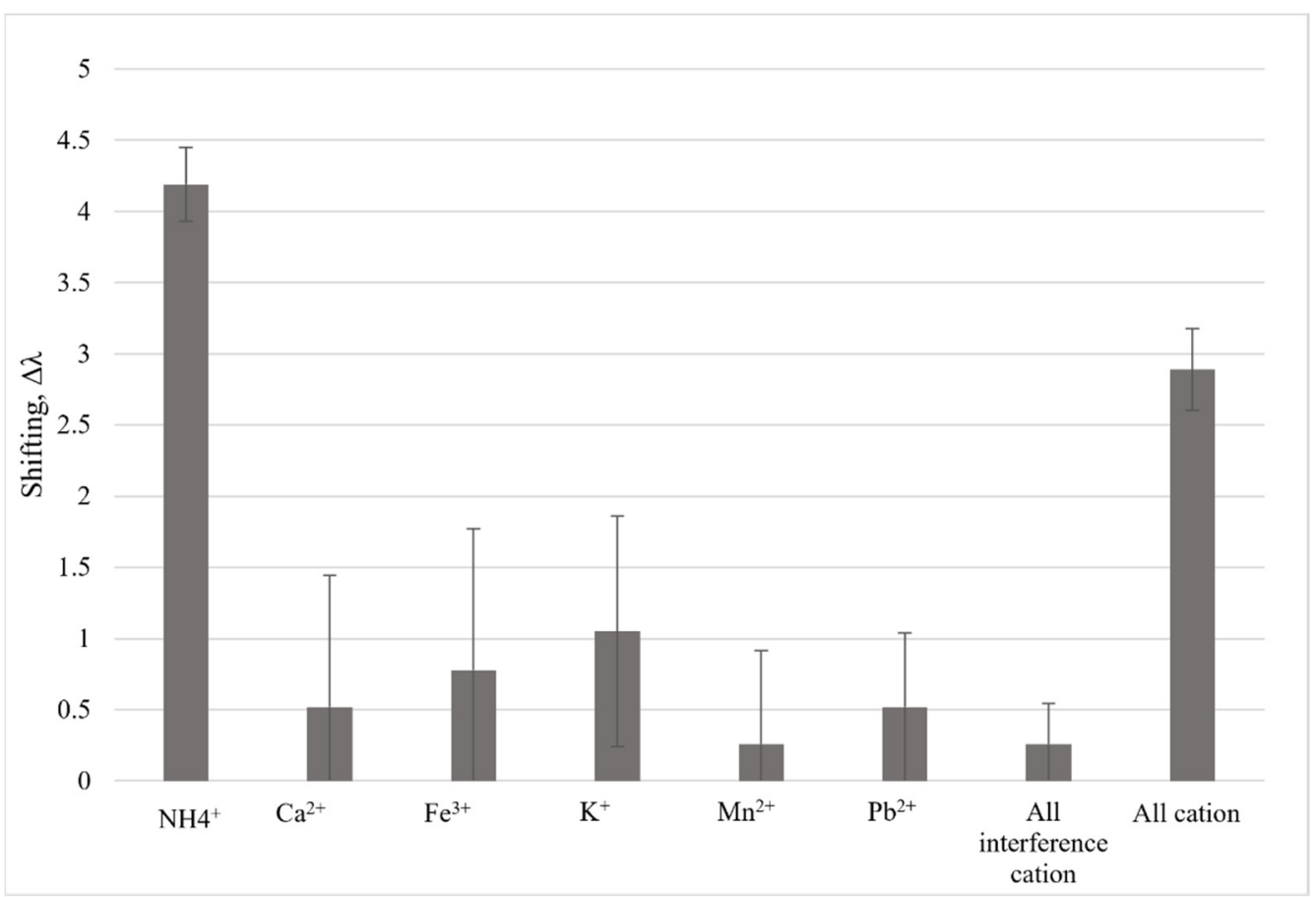

Figure 7. Selectivity test for AgNP-succinyl-k-carrageenan LSPR. 


\subsection{Interaction Mechanism Study}

The isotherm and kinetic model were used to study the interaction mechanism. The effect of pristine $\kappa$-carrageenan and succinyl- $k$-carrageenan dosage on the adsorption capacity of $\mathrm{NH}_{4}{ }^{+}$was shown in Figure 8a. The highest capacity adsorption of $\mathrm{NH}_{4}{ }^{+}$was observed at $0.1 \mathrm{~g}$, where succinyl- $\mathrm{k}$-carrageenan was $0.10 \mathrm{mg} / \mathrm{g}$ while $\mathrm{k}$-carrageenan was $0.04 \mathrm{mg} / \mathrm{g}$. These phenomena showed that succinyl- $\mathrm{k}$-carrageenan could adsorb a higher amount of $\mathrm{NH}_{4}{ }^{+}$compared to pristine $\mathrm{k}$-carrageenan. This proves that substituting succinyl group in $\mathrm{K}$-carrageenan provide more active sites for the interaction with $\mathrm{NH}_{4}{ }^{+}$. However, the adsorption capacity was gradually decreasing with the increase of adsorbent mass. This is due to the accumulation or overlapping of the active site onto the sorbent for both compounds. A similar result was also reported during the adsorption of arsenic ion on $\mathrm{Fe}_{3} \mathrm{O}_{4}$ /sugarcane bagasse activated carbon and aniline on graphene oxide, in which the increase of arsenic ion concentration leads to the reduction of adsorption capacity [12,24,25].
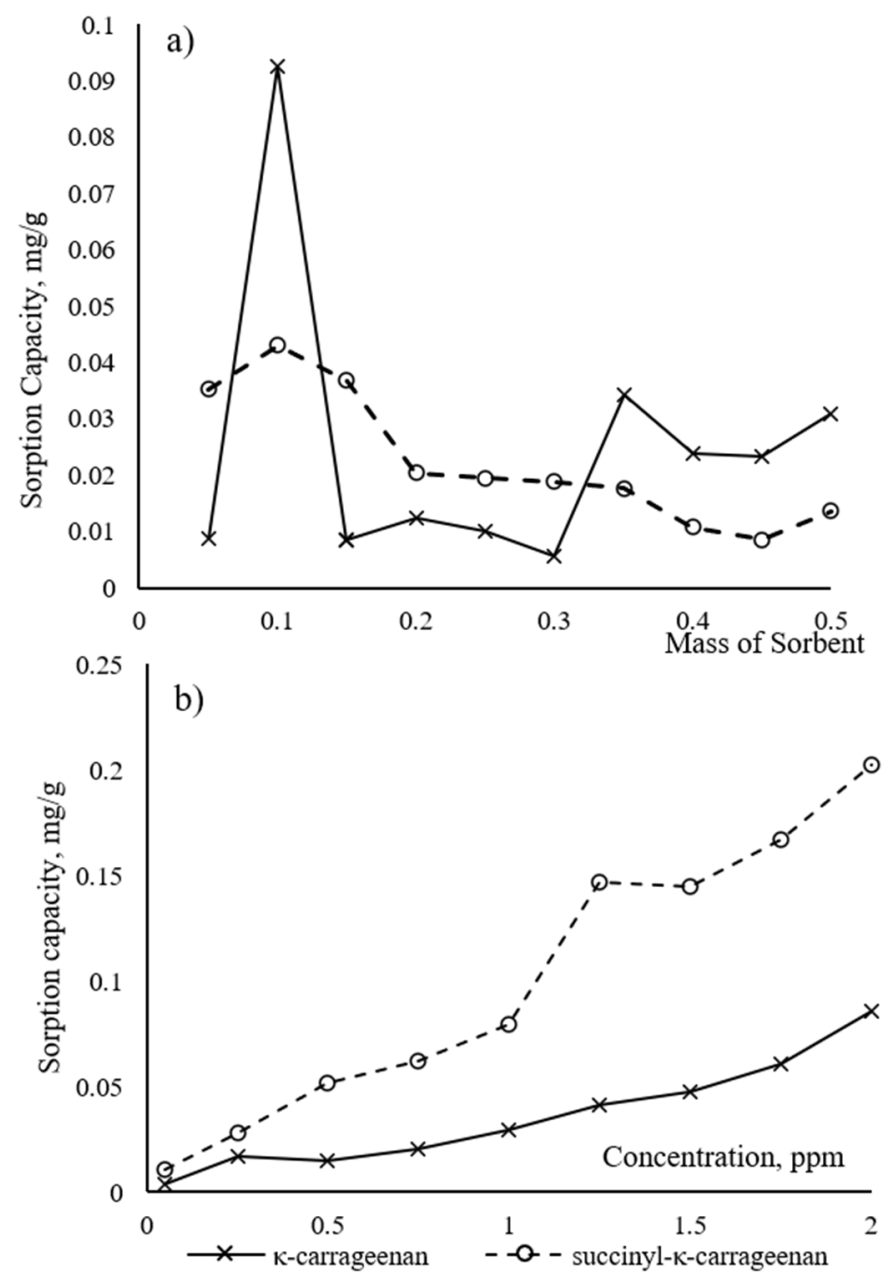

Figure 8. Effect of (a) adsorbent dosage on $\mathrm{NH}_{4}{ }^{+}$(b) initial $\mathrm{NH}_{4}{ }^{+}$concentration for $\mathrm{NH}_{4}{ }^{+}$adsorption on $\mathrm{k}$-carrageenan and succinyl-k-carrageenan.

Meanwhile, the effect of initial $\mathrm{NH}_{4}{ }^{+}$concentration is depicted in Figure $8 \mathrm{~b}$. The adsorption capacity increased with the increase of $\mathrm{NH}_{4}{ }^{+}$concentration for both compounds. The effective collision increased with the increase of $\mathrm{NH}_{4}{ }^{+}$concentration. A similar trend was also observed during the adsorption of $\mathrm{Cd}^{2+}$ and $\mathrm{Pb}^{2+}$ ions on chitosan and carboxymethyl cellulose. The heavy metal ion adsorption was first increased in response to the regular increases in metal ion concentrations [24,26]. At the concentration of $2 \mathrm{ppm}$ $\mathrm{NH}_{4}{ }^{+}$, the adsorption capacity of $\mathrm{NH}_{4}{ }^{+}$onto succinyl-k-carrageenan is twice higher than $\kappa$-carrageenan. This is due to higher electronegative density in succinyl-k-carrageenan 
compared to $\mathrm{K}$-carrageenan, that act as an extra available site for sorption of $\mathrm{NH}_{4}{ }^{+}$, hence, increased the performance of $\mathrm{NH}_{4}{ }^{+}$sorption. Enhancement of derivative compound performance also has been reported using modified chitosan. After modification, the metal ion adsorption capacity of modified chitosan was increased four times compared to unmodified chitosan [27].

Adsorption isotherm is an essential study describing how $\mathrm{NH}_{4}{ }^{+}$interact with the surface of $k$-carrageenan derivatives. Therefore, theoretical equations or empirical equations to correlate equilibrium data are necessary for adsorption understanding and adsorption degree estimation. Langmuir and Freundlich isotherm model equations can be used to interpret the obtained adsorption data. A linear plot of $C_{e} / q_{e}$ versus $C_{e}$ for Langmuir model and a linear plot of $\log \mathrm{Q}_{\mathrm{e}}$ versus $\log \mathrm{C}_{\mathrm{e}}$ for Freundlich model $\mathrm{NH}_{4}{ }^{+}$adsorption on $\mathrm{k}$-carrageenan and succinyl-k-carrageenan was shown in Figure $9 \mathrm{a}-\mathrm{d}$. The isotherm parameter was listed in Table 3. The linear regression of Freundlich isotherm presented the best fit to experimental data for both compounds as the correlation coefficient obtained is higher than Langmuir isotherm. This suggested that $\mathrm{NH}_{4}{ }^{+}$were adsorbed onto the $\kappa$-carrageenan and succinyl- $k$-carrageenan at multilayer adsorption with heterogenous energy distribution surface [11]. The value of $1 / n$ was less than 1 for both compounds, implying that chemisorption is favourable for the $\mathrm{NH}_{4}{ }^{+}$range being studied [11]. From isotherm and adsorption study, it can be construed that succinyl-k-carrageenan has higher $\mathrm{NH}_{4}{ }^{+}$adsorption capability than $\mathrm{k}$-carrageenan. It is due to the higher electronegative atom density of succinyl- $\mathrm{k}$-carrageenan compared to $\mathrm{k}$-carrageenan as supported by the AFM result (Figure 4).
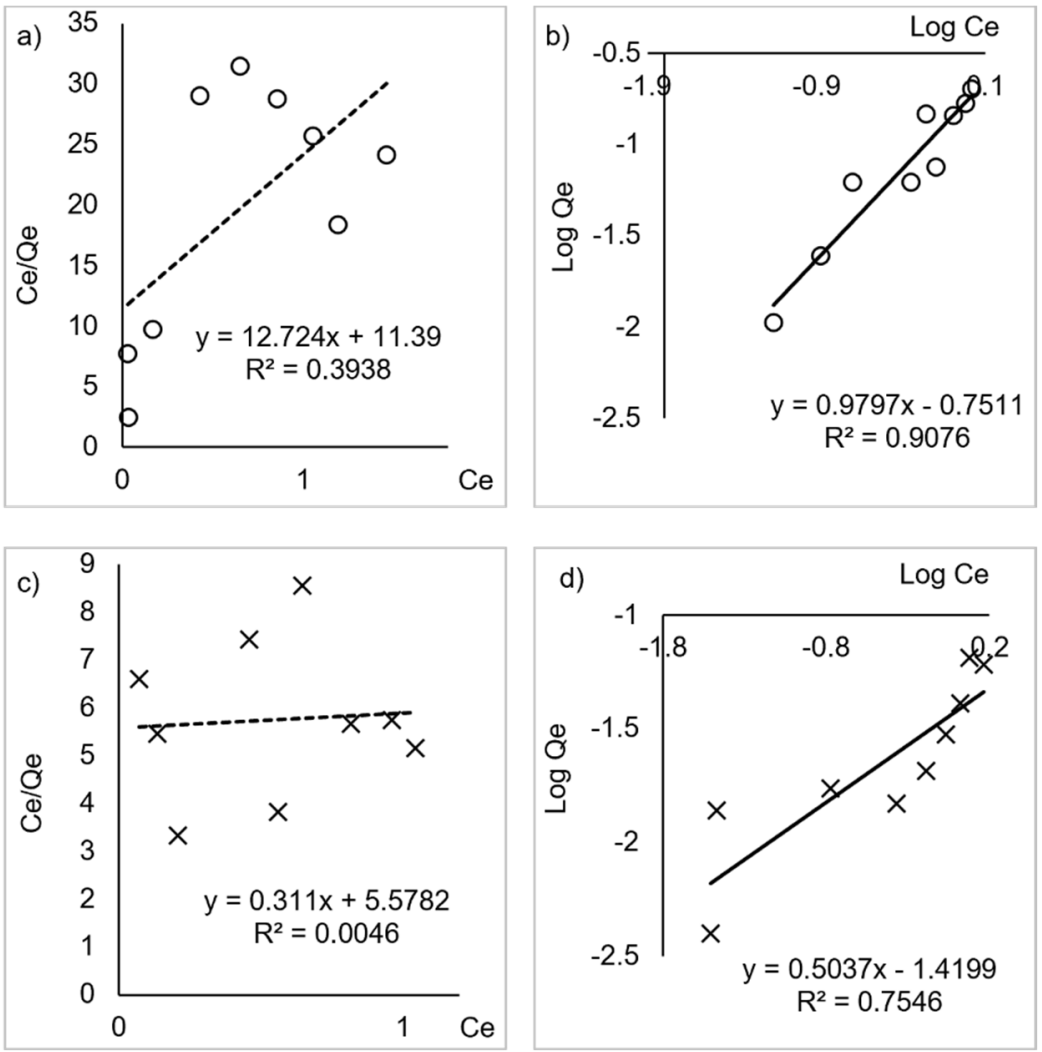

Figure 9. The linearized (a) Langmuir isotherm of $k$-carrageenan, (b) Freundlich isotherm of $k$ carrageenan, (c) Langmuir isotherm of succinyl-k-carrageenan, (d) Freundlich isotherm of succinyl-kcarrageenan. 
Table 3. Summary of adsorption isotherm and kinetic variable.

\begin{tabular}{cccc}
\hline $\begin{array}{c}\text { Isotherm and } \\
\text { Kinetic Model }\end{array}$ & Variable & к-Carrageenan & $\begin{array}{c}\text { Succinyl-k- } \\
\text { carrageenan }\end{array}$ \\
\hline \multirow{3}{*}{ Langmuir } & $\mathrm{Q}_{\max }(\mathrm{mg} / \mathrm{g})$ & 0.053 & 3.215 \\
& $\mathrm{~K}_{\mathrm{L}}(\mathrm{L} / \mathrm{mg})$ & 2.1679 & 0.0558 \\
& $\mathrm{R}_{\mathrm{L}}$ & 0.8218 & 0.9471 \\
Freundlich & $\mathrm{R}^{2}$ & 0.6138 & 0.0046 \\
\hline \multirow{3}{*}{ Pseudo-first-order } & $\mathrm{K}_{\mathrm{F}}\left(\mathrm{g} \mathrm{mg}^{-1} \mathrm{~min}^{-1}\right)$ & 0.0380 & 0.1774 \\
& $1 / \mathrm{n}$ & 0.5037 & 0.9797 \\
& $\mathrm{R}^{2}$ & 0.7546 & 0.9076 \\
\hline \multirow{2}{*}{ Pseudo-second-order } & $\mathrm{q}_{\mathrm{e}}\left(\mathrm{mg}_{1}\left(\mathrm{~min}^{-1}\right)\right.$ & 0.9911 & 1.0051 \\
& $\mathrm{R}^{2}$ & 3.8096 & 2.7102 \\
& $\mathrm{q}_{2}\left(\mathrm{~g} \mathrm{~min}^{-1}\right)$ & 0.2436 & 0.7947 \\
\hline
\end{tabular}

Meanwhile, Figure 10 shows the adsorption of $\mathrm{NH}_{4}{ }^{+}$onto $\mathrm{K}$-carrageenan and succinyl$\mathrm{K}$-carrageenan as a function of time. The adsorption capacity of $\mathrm{NH}_{4}{ }^{+}$onto $\mathrm{K}$-carrageenan and succinyl-k-carrageenan has reached its maximum at 10 and $60 \mathrm{~min}$, respectively, and no significant adsorption changed afterwards until $120 \mathrm{~min}$. The constant adsorption capacity started at the 10th minute for $\mathrm{k}$-carrageenan and 60th minute for succinyl- $\mathrm{k}-$ carrageenan is probably due to the total occupancy of active sites on adsorbent of both compounds. At this stage, the rate of adsorption and desorption of $\mathrm{NH}_{4}{ }^{+}$from the surface of $\kappa$-carrageenan and succinyl- $\kappa-$ carrageenan are equal [24]. A similar trend was also observed in the adsorption of $\mathrm{NH}_{4}{ }^{+}$using a hydrogel, whereby the adsorption reached equilibrium in $10 \mathrm{~min}$. Meanwhile, Cheng et al. 2017 reported that adsorption of $\mathrm{NH}_{4}{ }^{+}$ onto Na-rich birnessite has reached equilibrium within the first few minutes [28]. The pseudo-first-order and pseudo-second-order kinetic models were utilized to investigate the kinetic mechanism of $\mathrm{NH}_{4}{ }^{+}$adsorption onto succinyl-k-carrageenan and $\mathrm{k}$-carrageenan.

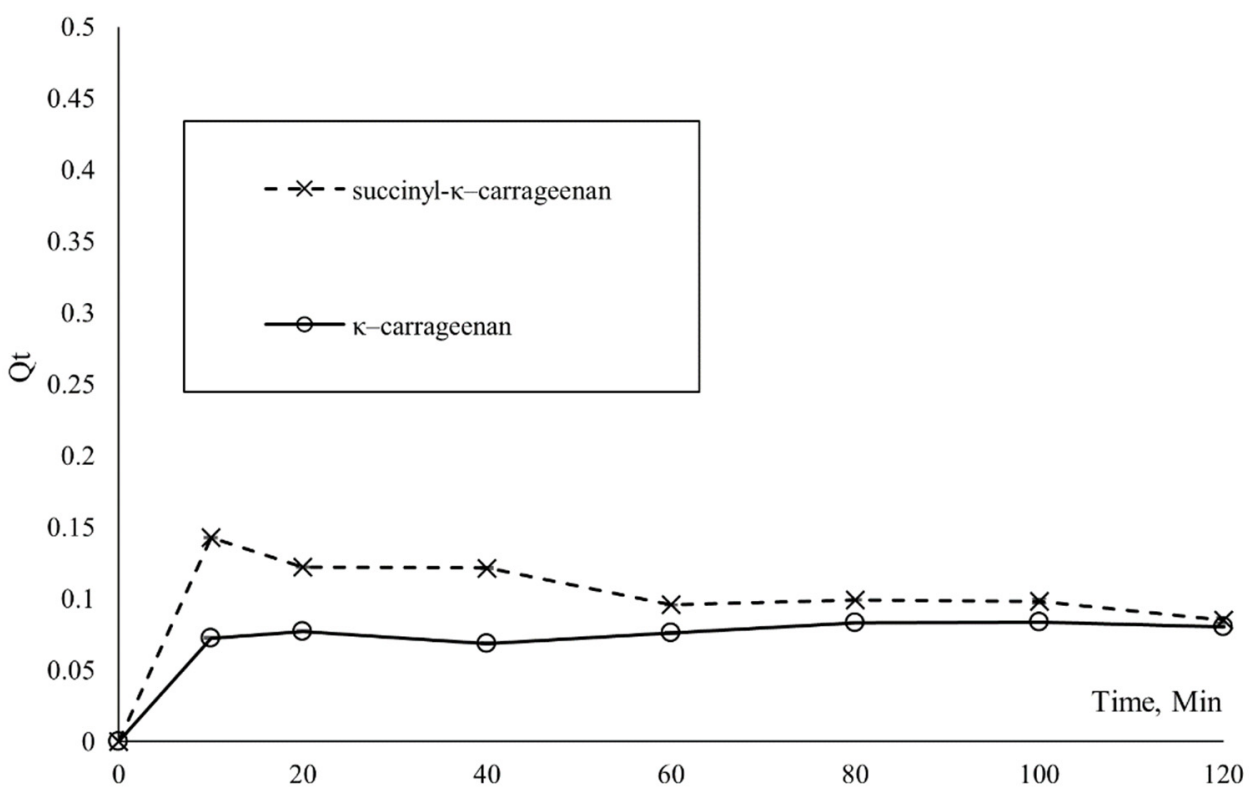

Figure 10. Adsorption of $\mathrm{NH} 4+$ onto $\mathrm{k}$-carrageenan and succinyl-k-carrageenan as a function of time.

Figure 11a-d shows the linearised pseudo-first-order and pseudo-second-order for $\kappa$-carrageenan and succinyl- $\mathrm{k}$-carrageenan. The calculated $\mathrm{q}_{\mathrm{e}}$, the rate constants and the 
correlation coefficient for two kinetic models of $k$-carrageenan and succinyl- $k$-carrageenan were shown in Table 3. The value of coefficient $\left(R^{2}\right)$ of pseudo-first-order and pseudosecond-order models for $\mathrm{K}$-carrageenan were 0.2436 and 0.9822 , respectively. The higher $\mathrm{R}^{2}$ value for $\mathrm{k}$-carrageenan indicates the data best fit for the pseudo-second-order model. Meanwhile, succinyl-k-carrageenan shows higher $\mathrm{R}^{2}$ for the pseudo-second-order model than pseudo-first-order with the value of $R^{2} 0.9863$ and 0.2781 , respectively, indicating the data was well fitted with pseudo-second-order. Pseudo-second-order assumed that adsorption of $\mathrm{NH}_{4}{ }^{+}$onto $\mathrm{K}$-carrageenan and succinyl- $\mathrm{k}$-carrageenan was through chemisorption supporting the result from Freundlich model in isotherm study [29]. It also suggested that the adsorption of $\mathrm{NH}_{4}{ }^{+}$onto succinyl- $\mathrm{K}$-carrageenan and pristine $\mathrm{k}$-carrageenan obeyed the pseudo-second-order kinetic indicated that the adsorption mechanism depended on the compound dosage and $\mathrm{NH}_{4}{ }^{+}$concentration. Pseudo-second-order suggested the initial adsorption of $\mathrm{NH}_{4}{ }^{+}$onto succinyl-k-carrageenan increase with the increase of $\mathrm{NH}_{4}{ }^{+}$. The lower the concentration of $\mathrm{NH}_{4}{ }^{+}$in the solution, the lower the effectiveness of $\mathrm{NH}_{4}{ }^{+}$ collision with the succinyl-k-carrageenan [13]. This finding was also observed in other research using biopolymer adsorbent, whereby the adsorption of methylene blue onto carboxymethyl cellulose/ $\mathrm{k}$-carrageenan/activated montmorillonite composite beads and agar/ $\mathrm{k}$-carrageenan composite hydrogel follows pseudo-second-order of reaction [14,30].
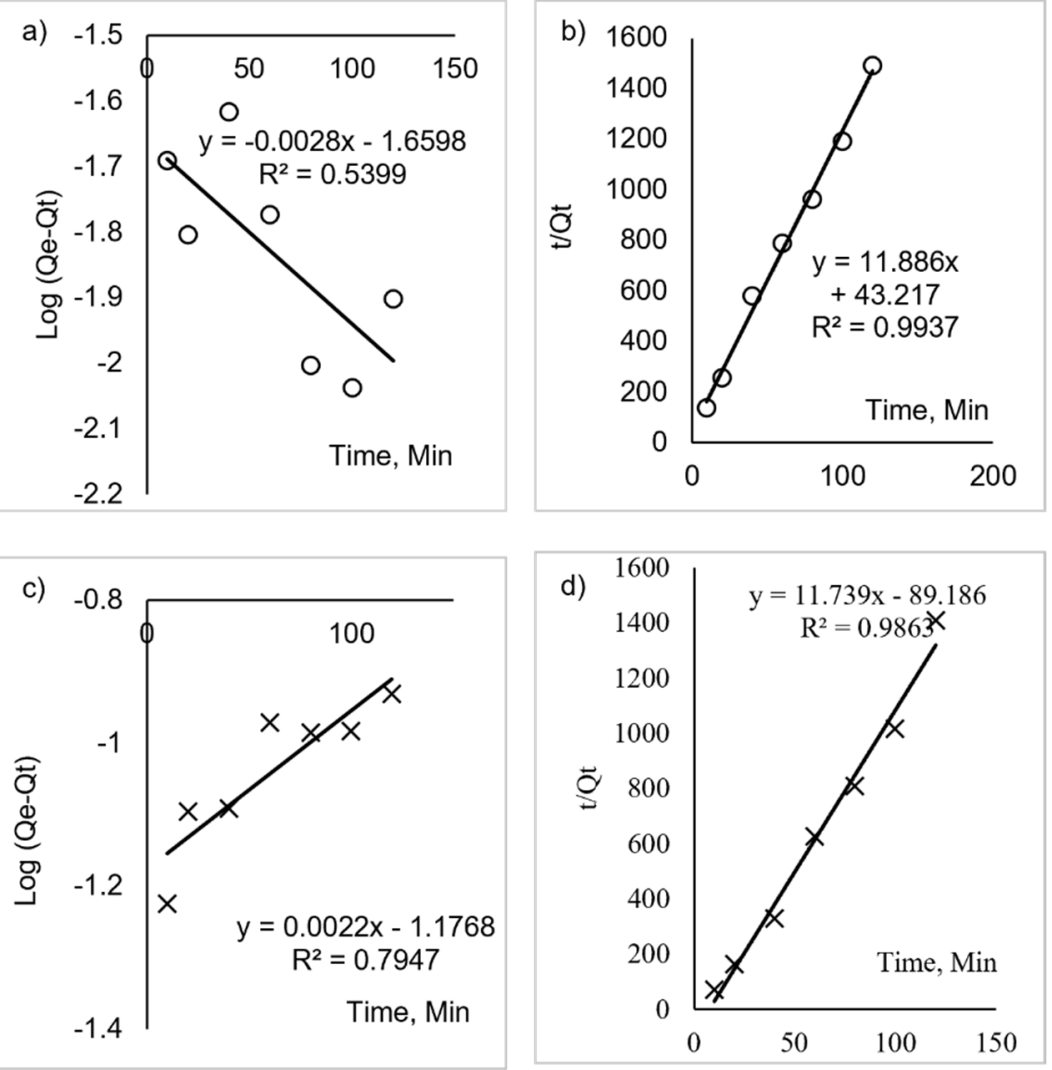

Figure 11. The linearized (a) kinetic pseudo-first-order of $k$-carrageenan, (b) kinetic pseudo-secondorder of $k$-carrageenan, (c) kinetic pseudo-first-order of succinyl-k-carrageenan, and (d) pseudosecond-order of succinyl-k-carrageenan.

\section{Conclusions}

Succinyl-k-carrageenan was successfully investigated for the enhancement of the $\mathrm{NH}_{4}{ }^{+}$LSPR sensor. Succinyl- $\mathrm{k}$-carrageenan was synthesised, and the performance of succinyl-k-carrageenan toward $\mathrm{NH}_{4}{ }^{+}$adsorption was compared with pristine $\mathrm{k}$-carrageenan. Based on the morphology analysis by FESEM, succinyl-k-carrageenan shows an even and featureless topology; meanwhile, $\mathrm{k}$-carrageenan displays an uneven surface with a wrinklelike surface. Succinyl-k-carrageenan was composited with AgNP on the salinized glass 
substrate for enhancement of LSPR sensor toward $\mathrm{NH}_{4}{ }^{+}$. AFM analysis demonstrates that the average surface roughness of AgNP-succinyl-k-carrageenan is far higher than the AgNP-K-carrageenan with the value of $198.535 \mathrm{~nm}$ and $27.265 \mathrm{~nm}$, respectively. The performance of the fabricated LSPR sensor toward $\mathrm{NH}_{4}{ }^{+}$using AgNP-succinyl-k-carrageenan as active material is better compared to AgNP-k-carrageenan. AgNP-succinyl-k-carrageenan LSPR shows higher sensitivity toward $\mathrm{NH}_{4}{ }^{+}$compared to AgNP-k-carrageenan LSPR. In addition, it offers a lower detection and quantification limits with the value of $0.5964 \mathrm{ppm}$ and 2.7192 ppm, respectively.

Furthermore, the fabricated LSPR sensor using AgNP-succinyl-k-carrageenan as sensing material has a better and broader range of detection up to $10 \mathrm{ppm}$ compared to the standard method. Selectivity test showed AgNP-K-carrageenan LSPR is highly selective toward $\mathrm{NH}_{4}{ }^{+}$. The interaction mechanism study shows that the adsorption of $\mathrm{NH}_{4}{ }^{+}$onto succinyl-k-carrageenan and pristine $\mathrm{k}$-carrageenan is well fitted Freundlich isotherm model and pseudo-second reaction suggesting the adsorption mechanism is through multilayer and chemical process. It is expected that the fabricated $\mathrm{NH}_{4}{ }^{+} \mathrm{LSPR}$ sensor based on biopolymer is highly potential to be used in future research, such as fiber optic LSPR sensor with the advantage of miniature, low cost, in situ and simple sensor technique.

Author Contributions: Investigation M.H.A.B. and N.A.A.N.; formal analysis, M.H.A.B. and N.A.A.N.; Writing-original draft preparation, M.H.A.B.; writing-review and editing, M.H.A.B., N.H.A., N.N.M. and A.A.A.B.; resource, A.R.M.Z. and. T.H.T.A.A.; conceptualization, A.A.A.B., N.H.A. and N.N.M.; supervision, A.A.A.B., N.H.A. and N.N.M.; funding acquisition, A.A.A.B., N.H.A. and N.A. All authors have read and agreed to the published version of the manuscript.

Funding: This research was funded by the Ministry of Higher Education Malaysia (M.O.H.E.), [Grant No: FRGS/1/2018/TK04/UKM/02/6] and Universiti Kebangsaan Malaysia under Grand Impact Fund (D.I.P.) [Grant No: DIP-2019-005].

Institutional Review Board Statement: Not applicable.

Informed Consent Statement: Not applicable.

Data Availability Statement: Not applicable.

Acknowledgments: The authors would like to thank the Photonics Technology Laboratory of the Department of Electrical, Electronic \& Systems Engineering, Faculty of Engineering and Built Environment, Department of Chemical Sciences, Faculty of Science and Technology, and the Center for Research and Instrumentation Management (CRIM), Universiti Kebangsaan Malaysia (U.K.M.) for all amenities provided.

Conflicts of Interest: The authors declare no conflict of interest.

\section{References}

1. Li, Q.P.; Zhang, J.Z.; Millero, F.J.; Hansell, D.A. Continuous colorimetric determination of trace ammonium in seawater with a long-path liquid waveguide capillary cell. Mar. Chem. 2005, 96, 73-85. [CrossRef]

2. Abu-Saied, M.A.; Wycisk, R.; Abbassy, M.M.; El-Naim, G.A.; El-Demerdash, F.; Youssef, M.E.; Bassuony, H.; Pintauro, P.N. Sulfated chitosan/PVA absorbent membrane for removal of copper and nickel ions from aqueous solutions-Fabrication and sorption studies. Carbohydr. Polym. 2017, 165, 149-158. [CrossRef]

3. Abdullah, S.; Azeman, N.H.; Mobarak, N.N.; Zan, M.S.D.; Bakar, A.A.A. Sensitivity enhancement of localised SPR sensor towards $\mathrm{Pb}$ (II) ion detection using natural bio-polymer based carrageenan. Optik 2018, 168, 784-793. [CrossRef]

4. Azeman, N.H.; Arsad, N.; Bakar, A.A.A. Polysaccharides as the Sensing Material for Metal Ion Detection-Based Optical Sensor Applications. Sensors 2020, 20, 3924. [CrossRef] [PubMed]

5. Sugunan, A.; Thanachayanont, C.; Dutta, J.; Hilborn, J.G. Heavy-metal ion sensors using chitosan-capped gold nanoparticles. Sci. Technol. Adv. Mater. 2005, 6, 335-340. [CrossRef]

6. Wei, J.L.Y.; Loh, K.S.; Ahmad, A.; Lim, K.L.; Wan, W.R. Synthesis and characterisation of modified k-carrageenan for enhanced proton conductivity as polymer electrolyte membrane. PLOS ONE 2017, 12, e0185313.

7. Abu Bakar, M.H.; Azeman, N.H.; Mobarak, N.N.; Mokhtar, M.H.H.; Bakar, A.A.A. Effect of active site modification towards performance enhancement in biopolymer k-Carrageenan derivatives. Polymers 2020, 12, 2040. [CrossRef]

8. Mobarak, N.N.; Jumaah, F.N.; Ghani, M.A.; Abdullah, M.P.; Ahmad, A. Carboxymethyl Carrageenan Based Biopolymer Electrolytes. Electrochim. Acta 2015, 175, 224-231. [CrossRef] 
9. Umar, A.A.; Salleh, M.M.; Bakar, N.A. Detection of creatinine on triangular silver nanoplates surface using surface-enhanced Raman scattering sensor. Int. J. Biomed. Nanosci. Nanotechnol. 2017, 3, 335. [CrossRef]

10. Bakar, N.A.; Shapter, J.G.; Salleh, M.M.; Umar, A.A. Self-Assembly of high density of triangular silver nanoplate films promoted by 3-aminopropyltrimethoxysilan. Appl. Sci. 2015, 5, 209-221. [CrossRef]

11. Foo, K.Y.; Hameed, B.H. Insights into the modeling of adsorption isotherm systems. Chem. Eng. J. 2010, 156, 2-10. [CrossRef]

12. Joshi, S.; Sharma, M.; Kumari, A.; Shrestha, S. Arsenic Removal from Water by Adsorption onto Iron Oxide/Nano-Porous Carbon Magnetic Composite. Appl. Sci. 2019, 9, 3732. [CrossRef]

13. Senthil Kumar, P.; Ramakrishnan, K.; Gayathri, R. Removal of nickel(II) from aqueous solutions by ceralite ir 120 cationic exchange resins. J. Eng. Sci. Technol. 2010, 5, 234-245.

14. Liu, C.; Omer, A.M.; Ouyang, X.-K. Adsorptive removal of cationic methylene blue dye using carboxymethyl cellulose/kcarrageenan/activated montmorillonite composite beads: Isotherm and kinetic studies. Int. J. Biol. Macromol. 2018, 106, 823-833. [CrossRef] [PubMed]

15. Lokman, N.F.; Azeman, N.H.; Suja, F.; Bakar, A.A.A. Sensitivity enhancement of Pb(II) ion detection in rivers using SPR-based Ag metallic layer coated with chitosan-graphene oxide nanocomposite. Sensors 2019, 19, 5159. [CrossRef]

16. Ma, J.; Liu, C.; Li, R.; Wang, J. Properties and structural characterization of chitosan/graphene oxide biocomposites. Biomed. Mater. Eng. 2012, 22, 129-135. [CrossRef]

17. Lokman, N.F.; Bakar, A.A.A.; Suja, F.; Abdullah, H.; Rahman, W.B.W.A.; Huang, N.M.; Yaacob, M.H. Highly sensitive SPR response of $\mathrm{Au} /$ chitosan/graphene oxide nanostructured thin films toward $\mathrm{Pb}$ (II) ions. Sens. Actuators B Chem. 2014, 195, 459-466. [CrossRef]

18. Nazri, N.A.A.; Azeman, N.H.; Luo, Y.; Bakar, A.A.A. Carbon quantum dots for optical sensor applications. Opt. Laser Technol. 2021, 139, 106928. [CrossRef]

19. Molins-Legua, C.; Meseguer-Lloret, S.; Moliner-Martinez, Y.; Campı'ns-Falco, P. A guide for selecting the most appropriate method for ammonium determination in water analysis. Trends Anal. Chem. 2006, 25, 282-290. [CrossRef]

20. Huang, Y.; Li, J.; Yin, T.; Jia, J.; Ding, Q.; Zheng, H.; Chen, C.T.A.; Ye, Y. A novel all-solid-state ammonium electrode with polyaniline and copolymer of aniline/2,5-dimethoxyaniline as transducers. J. Electroanal. Chem. 2015, 741, 87-92. [CrossRef]

21. Peters, J.J.; Almeida, M.I.G.S.; O'Connor Šraj, L.; McKelvie, I.D.; Kolev, S.D. Development of a micro-distillation microfluidic paper-based analytical device as a screening tool for total ammonia monitoring in freshwaters. Anal. Chim. Acta 2019, 1079, 120-128. [CrossRef]

22. Tang, S.; Cao, Z. Adsorption and dissociation of ammonia on graphene oxides: A first-principles study. J. Phys. Chem. C 2012, 116, 8778-8791. [CrossRef]

23. Tadi, K.K.; Pal, S.; Narayanan, T.N. Fluorographene based Ultrasensitive Ammonia Sensor. Sci. Rep. 2016, 6, 25221. [CrossRef] [PubMed]

24. Ray, S.S.; Gusain, R.; Kumar, N. Effect of reaction parameters on the adsorption. In Micro and Nano Technologies, Carbon Nanomaterial-Based Adsorbents for Water Purification; Ray, S.S., Gusain, R., Kumar, N., Eds.; Elsevier: Amsterdam, The Netherlands, 2020; pp. 119-135.

25. Fakhri, A. Adsorption characteristics of graphene oxide as a solid adsorbent for aniline removal from aqueous solutions: Kinetics, thermodynamics, and mechanism studies. J. Saudi Chem. Soc. 2017, 21, S52-S57. [CrossRef]

26. Manzoor, S.I.; Kaiser Ahmad, M.; Ahmad, S. Removal of Pb(II) and Cd(II) from wastewater using arginine cross-linked chitosancarboxymethyl cellulose beads as green adsorbent. R. Soc. Chem. 2019, 9, 7890-7902. [CrossRef]

27. Zhuang, S.T.; Yin, Y.N.; Wang, J.L. Simultaneous detection and removal of cobalt ions from aqueous solution by modified chitosan beads. Int. J. Environ. Sci. Technol. 2018, 15, 385-394. [CrossRef]

28. Cheng, Y.; Huang, T.; Shi, X.; Wen, G.; Sun, Y. Removal of ammonium ion from water by Na-rich birnessite: Performance and mechanisms. J. Environ. Sci. 2017, 57, 402-410. [CrossRef] [PubMed]

29. Spies, A.R.L.; Wewers, F. Equilibrium, kinetics and thermodynamics studies of Cd sorption onto a dithizone-impregnated Amberchrom CG-300m polymer resin. Arab. J. Chem. 2020, 13, 5050-5059. [CrossRef]

30. Duman, O.; Polat, T.G.; Diker, C.Ö.; Tunç, S. Agar/k-carrageenan composite hydrogel adsorbent for the removal of Methylene Blue from water. Int. J. Biol. Macromol. 2020, 160, 823-835. [CrossRef] [PubMed] 